\title{
MONITORIA UM DISPOSITIVO DE ENSINO E APRENDIZAGEM COM O USO DAS TICS EM UM LABORATÓRIO DE INFORMÁTICA
}

\author{
Elisandro Rodrigues - Especialista /UFRGS - elisandromosaico@gmail.com \\ Roger de Abreu Silva - Mestrando/PUCRS - rogerabreumat@gmail.com
}

\begin{abstract}
Resumo: O presente artigo busca apresentar a monitoria como dispositivo e como forma de ensino e de aprendizagem. Os alunos monitores são estudantes das séries finais do ensino fundamental que aplicam atividades para alunos de séries iniciais do ensino fundamental. A aplicação das atividades é mediada pelo Professor Laboratorista. Neste trabalho apresentamos resultados parciais das repercussões de um projeto de monitoria desenvolvida em um laboratório de informática, realizado em uma escola da rede municipal do município de Sapucaia do Sul, apresentamos o contexto histórico da importância da monitoria em ambientes de aprendizagem e diferentes aplicações das TICs para o ensino de matemática, além de relatar resultados da investigação do projeto desenvolvido.
\end{abstract}

Palavras-chave: aprendizagem, monitoria, dispositivo, laboratório de informática, informática na educação.

\section{MONITORING DEVICE FOR TEACHING AND LEARNING WITH THE USE OF TIC IN A COMPUTER LAB}

Abstract: This article aims to show how the monitoring device and as a way of teaching and learning. Monitors are students from 6o.-9o. Year that are applying activities for students on the early grades of elementary school. The implementation of activities is mediated by Teacher Labourer. This paper presents partial results of the impact of a project monitoring developed in a computer lab, conducted on a school from the city in the South of Brasil. We present the historical context of the importance of monitoring in different learning environments and applications of TICs for teaching mathematics, in addition to reporting research results of the project developed.

Keywords: learning, monitoring, device, computer lab, computers in education.

\section{Introdução}

O presente artigo tem como objetivo relatar a investigação em uma escola pública do Município de Sapucaia do Sul, onde é realizado um projeto de monitoria em um Laboratório de Informática com alunos do Anos Finais do Ensino Fundamental. Apresentamos o contexto histórico da monitoria na educação e sua importante relação com o ensino e a aprendizagem com o uso das TICs após apresentamos uma teorização da monitoria como um dispositivo e apresentamos algumas conclusões do projeto desenvolvido nessa escola.

Historicamente, a monitoria está presente na educação desde o período Medieval. Há relatos sobre alunos que reproduziam a matéria que seus mestres desenvolviam. (ULLMANN E BOHNEN, 1994).

Manacorda (1999) relata que nos séculos XIV e XV os monitores estavam presentes junto aos professores, eram denominados por repetidores (Proscholus, nome latino) e havia contratos para professores onde o monitor constava. 
Para Monroe (1974), o monitor era visto na antiguidade clássica como o pedagogo que realizava junto com o mestre, atividades de monitoria, simplificando a aula dos mestres. Segundo o mesmo autor, na idade média os monges desempenhavam o papel de monitores na educação dos noviços. Na Inglaterra, em 1797, já se fazia menção a monitores como alunos mais velhos que instruíam os mais novos. Joseph Lancaster (1778-1838) desenvolveu um método de ensino com monitores na Inglaterra, substituindo o sistema tradicional, podendo assim um professor controlar uma escola de 1000 alunos com a ajuda de seus monitores, conforme descrição abaixo:

\begin{abstract}
o método lancasteriano baseia-se no ensino dos alunos por eles mesmos, divididos em várias classes, seis em geral, todos com nível de conhecimento semelhante, ou seja, nenhum aluno sabe nem mais nem menos que o outro. $\mathrm{O}$ aluno é integrado a uma classe, depois de averiguado seu conhecimento. A classe tem um ritmo determinado de estudo e um programa a desenvolver de leitura, escrita e aritmética. Cada aluno pode pertencer, ao mesmo tempo, a várias classes diferentes: pode estar mais avançado em leitura do que na escrita ou no cálculo. (BASTOS, 2011, p.3)
\end{abstract}

Nesse método, a função do professor é restrita, não tendo contato direto com os alunos, apenas com os monitores antes do início da aula. No decorrer da aula, o professor permanece em sua mesa, a frente da sala, apenas olhando do alto e é assistido por um ou dois monitores, os mais velhos e mais experientes, que transmitem suas ordens e o substituem em caso de falta.

Para avaliar a grande quantidade de alunos, o professor impõe ordens por meio de apitos e bastões e controla o fluxo de alunos, as mudanças de exercícios, regulariza o trabalho dos monitores. Caso seja preciso, pune o monitor por abuso de poder. O telégrafo é o instrumento que assegura o diálogo entre o professor e o monitor geral e os demais monitores. (BASTOS, 2011)

A criação do método lancasteriano foi disseminada no mundo nas primeiras décadas do século XIX, tendo o monitor um papel importantíssimo na descentralização da figura do professor, rompendo o discurso pedagógico de Comenius e da tradição lassaliana, com suas regras rígidas e de penitência dadas pelo professor. Como o método lancasteriano tinha como objetivo proporcionar a educação em massa para as classes populares (NARODOWSKI, 2008), passou a ser adotado pelos países da América Latina neste mesmo período. No Brasil o método foi implementado no final da década de 1810 sendo oficializado pelo Decreto das Escola das Primeiras Letras de 15/10/1827. O método lancasteriano nas escolas brasileiras teve influência da maioria dos manuais utilizados pelos educadores brasileiros, vindos da França. Portanto, no Brasil, a influência lanscasteriana não teve seu embasamento nas origens inglesas, mas das leituras e apropriações dos franceses.(BASTOS, 2005).

No Brasil, esse método não foi bem aceito e em 1840 foi implementada a instrução simultânea, na qual o professor ensina a todos os alunos ao mesmo tempo substituindo o ensino mútuo, no qual o monitor atende o aluno com suas dúvidas enquanto os demais cumprem suas tarefas de aula.

Na atualidade, a monitoria é desenvolvida em vários ambientes de formação, em escolas públicas, particulares e universidades, desempenhando uma papel importante no desempenho escolar dos alunos.

Nossos alunos possuem muitas habilidades, e uma delas é a capacidade de serem solidários com os colegas, Assim, os alunos ao exercerem o papel de monitores, compartilham experiências, aproximando-se dos colegas que apresentam fragilidades na aprendizagem, conseguindo perceber dificuldades que o professor muitas vezes não consegue discernir de imediato. (DURAN E VIDAL, 2007) 
Para o aluno monitor, a atividade de monitoria proporciona vários benefícios que podemos enumerar: a aprendizagem interdisciplinar; a compreensão de conteúdos; o conhecimento de diferentes metodologias de ensino; o diálogo com o professor na solução de problemas; a produção de conhecimento (SCHNEIDER 2006); o desenvolvimento da autonomia (DURAN E VIDAL, 2007); o resgate de dificuldades ocorridas em sala de aula e a proposição de alternativas para tentar superá-las. (AMORIN, 2012)

Nesse sentido, enxergamos a monitoria como uma possibilidade de qualificar os processos de ensino e de aprendizagem, permitindo aos alunos envolvidos a construção de conhecimentos que utilizarão em sua formação como cidadãos atuantes, atendendo às exigências da sociedade contemporânea.

Nesse contexto, em junho de 2012, foi criado o Projeto Monitoria no Laboratório de Informática na escola em questão, onde encontramos alunos interessados em participar voluntariamente de um projeto no Laboratório de Informática que o objetivo de: verificar as mudanças de atitudes que a participação em um projeto de monitoria em um Laboratório de Informática provoca nos alunos-monitores, verificar os conhecimentos matemáticos construídos pelos monitores; analisar as contribuições de um projeto de monitoria em para os processos de ensino e de aprendizagem na área de matemática.

O Projeto de monitoria fundamenta-se em autores como Valente (2001), Weiss (2001), Silva (2004), Papert (2007), Kenski(2007) entre outros pesquisadores da Informática na Educação, em seus diferentes aspectos. As contribuições do uso pedagógico das TICs para o ensino e a aprendizagem dos alunos são destacadas pelos referidos autores. Dentre eles, Valente (2001) destaca como contribuições importantes a motivação para a aprendizagem e o desenvolvimento da criatividade.

Vivenciamos a era da tecnologia, e quando falamos em aulas de matemática, os alunos têm a ideia de aulas cansativas, pouco compreensíveis e nas quais a aprendizagem é desgastante. Como alternativa para superar essa realidade, Moran et al. (2001, p. 102) sugere que os professores elaborem planos e estratégias de ensino, incorporando as Tecnologias de Informação e Comunicação, pois dessa forma o aluno poderá aprender de acordo com o seu ritmo e seu estilo. Além disso:

\footnotetext{
nesse novo processo educativo, o aluno dispõe de recursos para avançar, pausar, retroceder e rever o conhecimento. Esse processo permite fazer anotações e investigações pessoais, consultar materiais alternativos e complementares, bem como discutir com outros usuários ou com os próprios colegas suas produções. (MORAN et al., 2001, p.102)
}

Ao incorporar os recursos tecnológicos a sua aprendizagem, o aluno monitor passa a fazer uso das seguintes ações: projetar, criar, produzir conhecimento, superando as ações repetidas e maçantes que o faziam estar desinteressado como: escutar, ler, decorar e repetir.

Um importante aliado da aprendizagem de matemática é o uso das TICs em suas no laboratório de informática. Nele, o aluno tem acesso a ferramentas fundamentais para a compreensão de conceitos matemáticos. Além disso, as TICs proporcionam às aulas de matemática um ambiente lúdico, favorável à aprendizagem.

O laboratório de informática permite disponibilizar recursos importantes ao ensino de matemática, tais como softwares matemáticos e jogos eletrônicos,. Tais recursos quando utilizados adequadamente, auxiliam na construção de conhecimentos em diversas áreas. 
No que se refere ao ensino de matemática, um software que pode ser utilizado no Laboratório de Informática é o Logo. Segundo Valente (2001, p. 21), a aprendizagem da linguagem de programação Logo

\begin{abstract}
parte do suposto de que é o aluno quem constrói a sua hipótese, executa-a por meio da linguagem de programação, observa os resultados desenvolvidos pelo computador na forma de um desenho. Se o aluno não estiver de acordo com os resultados, tem a oportunidade de depurar, de refazer seu trabalho, reiniciando as etapas e, desta forma, vai construindo sua aprendizagem de maneira simples e prazerosa.(VALENTE, 2001, p.21).
\end{abstract}

É importante que as escolas utilizem recursos tecnológicos, apostando em novos percursos de aprendizagem, criando estratégias pedagógicas que aproximem o aluno de seu professor e que promovam a sociabilização do conhecimento. Portanto, é fundamental a valorização de projetos que contemplem o uso de TICs e o acesso a formações continuadas de cunho tecnológico aos educadores, para que a utilização do computador não reproduza o ensino tradicional.

Com relação ao uso das TICs na área de matemática, Borba (2010) apresenta no contexto do Grupo de Pesquisa em Informática, outras Mídias e Educação Matemática (GPIMEM), algumas repercussões do uso de TICs na Educação Matemática. Ele afirma que, desde 1993, pesquisadores da área de Educação Matemática têm traçado uma trajetória de investigações que evidenciam resultados favoráveis no que se refere ao uso das Tecnologias de Comunicação e Informação nas aulas de Matemática.

Pesquisas têm evidenciado que um dos principais recursos tecnológicos na área da matemática são os softwares. Seu uso possibilita: investigar as diferentes formas de construções geométricas (SANTOS, 2008); um maior feedback, devido ao seu aspecto visual (BORBA; VILLAREAL, 2005); o pensamento coletivo, entre alunos e professores atuando no processo de “fazer” matemática (LÉVY, 1993); a criação de conjecturas e validação no processo de demonstrações matemáticas (ZULATTO, 2002), assim como sua refutação (LABORDE, 2000).

Para que as possibilidades dos softwares sejam exploradas nas escolas é necessário compreendê-la. Isso exige do educador matemático formação continuada que contemple o uso das TICs na área da matemática.

No decorrer dos anos, espera-se que as crianças aprendam nas escolas o que pode ter utilidade em suas vidas e, principalmente, algo que irão precisar em sua vida profissional. Quando chegam ao mundo do trabalho, o que mais necessitam utilizar do ambiente escolar é a capacidade de aprender novas habilidades e novos conceitos, avaliar situações, lidar com o inesperado. Para Papert (2007) a habilidade competitiva no futuro será a capacidade de aprender.

O uso das TICs no ensino contribuem para o desenvolvimento intelectual das crianças e tornam a aprendizagem mais divertida. Os jogos no computador, por exemplo, proporcionam o divertimento e a motivação. Para Papert (2007, p. 12), “[...] os videogames ensinam às crianças o que os computadores estão começando a ensinar aos adultos - que algumas formas de aprendizagem são rápidas, muito atraentes e gratificantes".

O autor defende também a ideia de que é necessário “[...] ensinar de forma a produzir a maior aprendizagem a partir do mínimo de ensino”, sendo que não se pode atingir este objetivo apenas retirando quantidades de ensino, mas adequando a forma de ensinar. Além disso, para que ocorra a aprendizagem, a motivação é fundamental, pois "se as crianças realmente desejam aprender algo e têm a oportunidade de aprender em uso, elas o fazem mesmo quando o ensino é fraco.” (PAPERT, 2007, p. 125). 
Para desenvolver uma proposta pedagógica consistente, que incorpore as TICs, o professor precisa estar fundamentado e atualizado quantos ao uso das TICs em sua área; assumir atitude reflexiva, ou seja, questionar-se constantemente sobre como utilizar as Tecnologias de Comunicação e Informação em seus planejamentos.

O professor, familiarizado com as TICs, pode elaborar atividades pedagógicas e projetos adaptados aos recursos disponíveis em seu ambiente escolar, desafiando seus alunos para a aprendizagem. No caso das escolas públicas, o ambiente propício para que isso ocorra é o laboratório de informática,

O projeto de monitoria no Laboratório de Informática é desenvolvido da seguinte maneira: durante quatro dias da semana, de dois a três monitores auxiliam no laboratório nos turnos da manhã e da tarde - das $07 \mathrm{~h} 50$ às $11 \mathrm{~h} 50$ e das 12 horas e 50 minutos às 16 horas e 50 minutos. O trabalho se desenvolvia da seguinte maneira: pela parte da manhã as turmas do pré ao quinto ano foram atendidas quinzenalmente em períodos de 80 minutos. Em alguns momentos as turmas vinham junto com o professor titular e em outros, dependendo do trabalho desenvolvido, a turma se dividia em duas. Com exceção dos dois primeiros anos e os dois segundos, essas turmas eram atendidas em um período de 40 minutos toda sexta feira, alterando apenas a ordem dos períodos.

Pela parte da tarde as turmas do pré ao quinto ano são atendidas quinzenalmente, em períodos de 80 minutos, divididas em dois momentos (metade da turma vai ao laboratório junto com o professor responsável pelo Laboratório de Informática, durante 40 minutos, e o restante da turma, após este horário). Como exceção, duas turmas, uma de quarto ano e uma de quinto ano, são atendidas semanalmente, em períodos de 40 minutos, sem divisão da turma, conforme combinação feita com os professores regentes.

Os monitores ajudam no planejamento das aulas, elaborando atividades adequadas ao público-alvo do dia e, durante as aulas no laboratório, auxiliam os colegas que apresentam dificuldades. Após, elaboram relatórios, relatando o desenvolvimento da aula, comentando o que foi bom ou ruim, quais dificuldades sentiram ao atender determinados alunos, o que sugerem para melhorar o trabalho realizado com os colegas, entre outros.

\section{Projeto Monitoria como Dispositivo}

O projeto de Monitoria ressoa de diferentes modos na vida dos alunos monitores. Percebemos que esse espaço é ocupado com tons e posturas diferentes e com uma maneira distinta da sala de aula "normal". Para os alunos a monitoria é um entre (Deleuze, 2005; Primo, 2005), onde existe a possibilidade deles potencializarem suas ações, seus gostos, seus jeitos, fazer algo novo, criar algo único nos processos de vida deles e nos apredizados. Gostaríamos de pensar nesse espaço da Monitoria em um Laboratório de Informática como um dispositivo, como um entre.

O Projeto de Monitoria é um fio, uma linha que produz sujeitos, sendo assim um dispositivo do entre, do conhecimento e da informação, e além disso um dispositivo pedagógico. Se configura como um "desvio para o novo”, uma lin a que traça outros escritos, "as lin as de subjectivação parecem ser particularmente capazes de traçar camin os de criação, que não cessam de fracassar, mas que também, na mesma medida, são retomados, modificados”( DELEUZE, 1996, p. 4).

Costura-se assim nesses alunos monitores um espaço onde a potencialização de outros saberes agencia-se com os saberes "formais" da sala de aula, conecta eles em um outro gosto pelo aprender. O Projeto Monitoria no LABIN é um dispositivo quando os alunos monitores se colocam como protagonistas do seu fazer e enfrentam os desafios 
do dia a dia no Laboratório de Informática: como quando os alunos monitores devem ajudar nos processos de aprendizagem dos alunos usuários do LABIN; nas construções de um raciocínio lógico; de uma escrita, de um relato sobre as turmas atendidas. Esse novo faz com que eles sejam instigados a pensar, sejam protagonistas do seu saber, produzam a si mesmos [subjetivação], e com isso produzam outras linhas por eles mesmos, saindo assim, de um lugar de invisibilidade para um lugar de visibililidade.

\section{Metodologia}

A pesquisa desenvolvida é de cunho qualitativo, que visa aprofundar a compreensão acerca dos fenômenos que investiga, analisando rigorosamente e criteriosamente as informações obtidas., “[...] não pretendendo testar ipóteses para comprová-las ou refutá-las ao final da pesquisa; a intenção é a compreensão, reconstruir conhecimentos existentes sobre os temas investigados.” (MORAES; GALLIAZZI, 2007, p.11).

Em um estudo de cunho qualitativo pretende-se compreender um determinado fenômeno, não se preocupando unicamente com seus princípios, leis e generalizações, mas com o que possui significado ao pesquisador, respondendo aos seus objetivos (BICUDO, 2005).

\section{O uso da TIC no Projeto Monitoria no Laboratório de Informática}

No desenvolvimento das aulas no Laboratório, os alunos monitores possuem autonomia para criar e desenvolver atividades, um exemplo de atividade, com aplicação das TICs com o uso do software Logo, utilizando noções espaciais, motivou os monitores a desafiar os alunos do quarto e quinto ano do Ensino Fundamental, descrevemos a atividade aplicada:

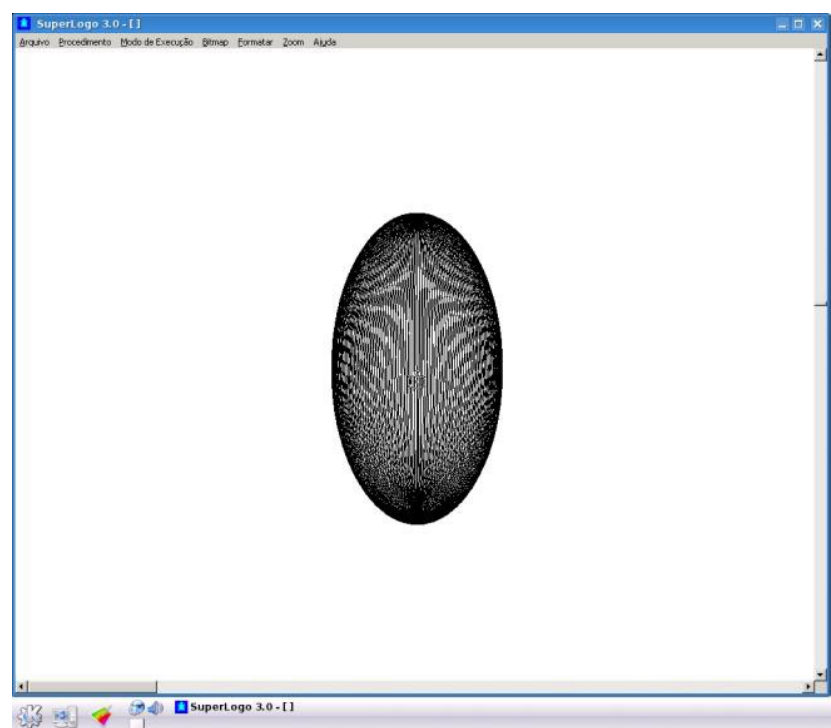

Figura 1: construção de elipsoide, com o uso dos comando: logo3d repita 40 [ arcoelipse 360100200 100 rolepd 2]

O desafio nessa atividade era de que o Logo poderia construir figuras tridimensionais em que os alunos não estavam acostumados a enxergar na geometria, para isso, os alunos monitores desafiaram os alunos a criarem rotações e translações. Para isso foram feitos questionários antes e após a atividade sobre os conceitos.

A maioria dos alunos tiveram dificuldades em definir o conceito de rotação e translação conforme resposta abaixo: 

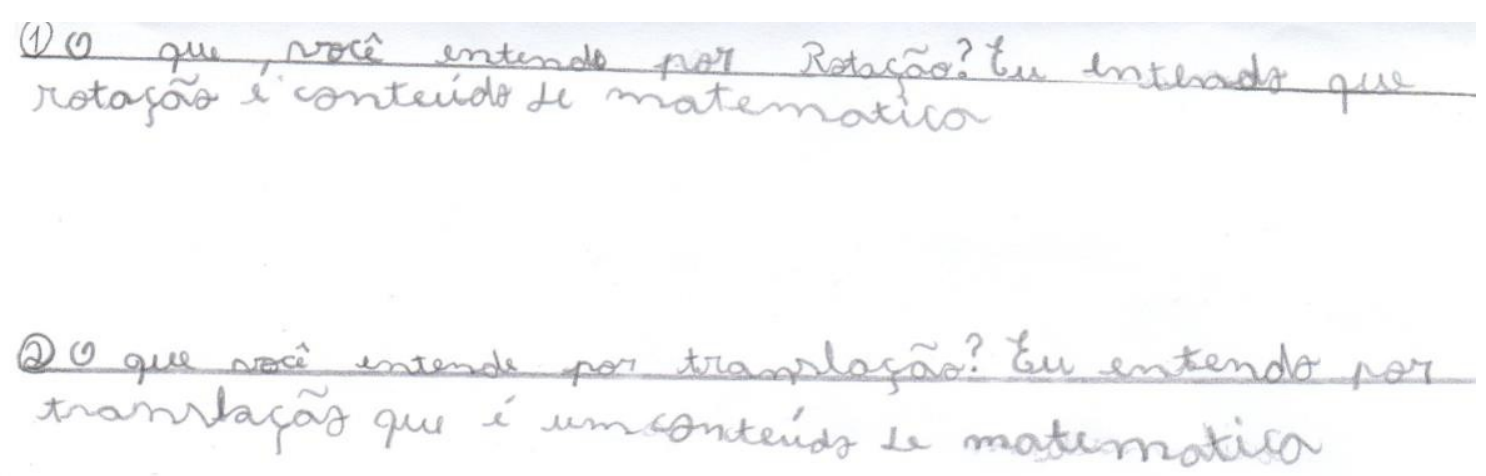

Figura 2: Resposta a duas questões do questionário de um aluno do 4 ano antes da atividades no laboratório.

Após a atividade de translação e rotação no laboratório os alunos evoluíram muito na definição dos conceitos, compreedendo que a rotação não altera a figura conforme resposta de um dos alunos abaixo:

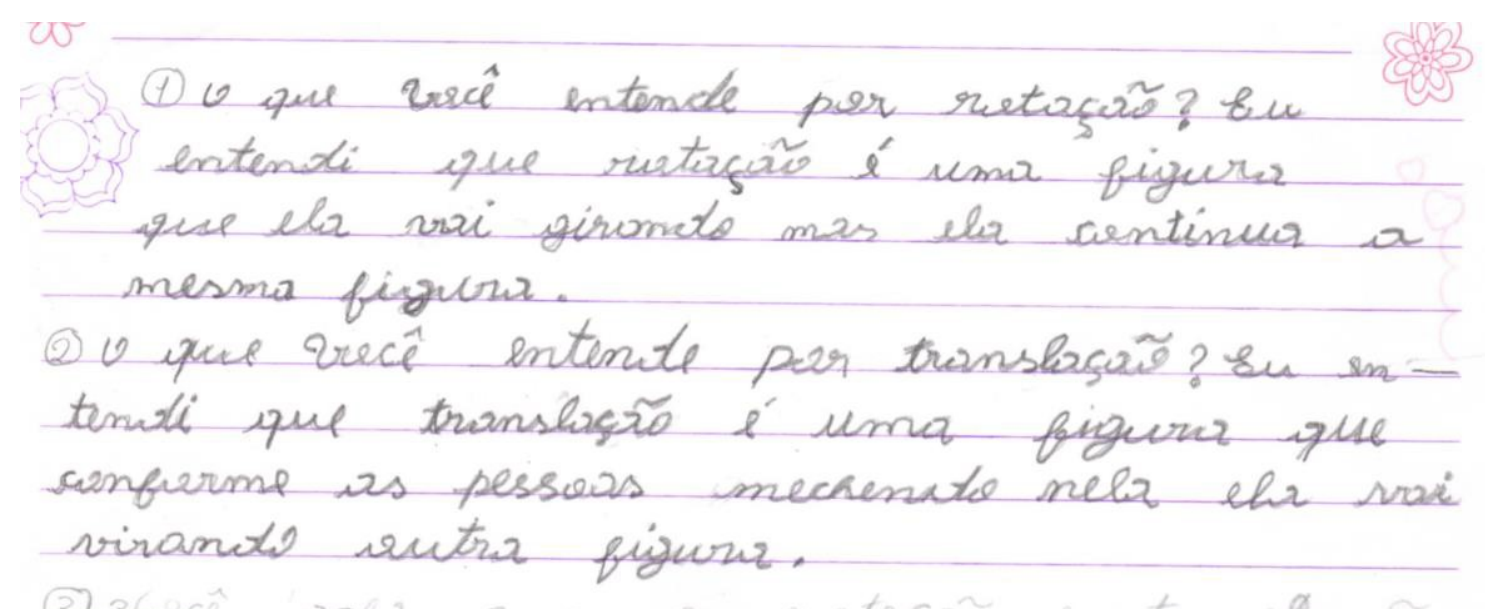

Figura 3: Resposta a duas questões do questionário de um aluno do $4^{\circ}$ ano, após as atividades no laboratório.

\section{Conclusões}

No desenvolvimento do projeto Monitoria no Laboratório de Informática foi possível evidenciar algumas repercussões, por meio dos dados coletados e analisados até o momento, como mudança de atitudes dos alunos monitores com relação à aprendizagem, construção de conhecimentos, motivação para aprender e desenvolvimento da autonomia.

Não é importante só para os alunos monitores esse processo, mas nós, enquanto professores laboratoritas, também costuramos outras linhas de subjetivação. Aprendemos nas relações e nas mediações que aparecem todo o dia. Schérer (2005, p. 1188), diz que:

aprender não é reproduzir, mas inaugurar; inventar o ainda não existente, e não se contentar em repetir um saber "fala-se - percorro outra vez o mesmo texto -, do fundo daquilo que não se sabe, de seu próprio sentido, de seu próprio desenvolvimento, de um conjunto de singularidades soltas”; pois é preciso desfazer os "aparel os de saber”, as organizações preexistentes, incluída a do corpo, para devir, entrar em "devires” que comandam e balizam toda criação. 
Outros devires é o que esse projeto de Monitoria proporciona não parecermos tanto presunçosos, mas que em linhas de subjetivação está mudando tanto os alunos monitores quanto nós, professores do Laboratório. Mas, cabe lembrar, em consonância com Kenski (2007, p.101) que fala que "as TIC’s exigem transformações não apenas nas teorias educacionais, mas na própria ação educativa e na forma como a escola e toda a sociedade percebem sua função na atualidade”. As ações educativas estão começando a mudar, agora cabe saltarmos para outros processos dentro da Escola, outros projetos que englobem outras linhas.

\section{Referências}

AMORIN, Roseane Maria de; LIRA, Tatiane Hilário de; OLIVEIRA, Michele Pereira de; Palmeira, Ana Paula. O papel da monitoria para a formação de professores: cenários, itinerários e possibilidades no contexto atual. In: Revista Exitus, Volume 02, $\quad \mathrm{n}^{\circ}$ 02.Jul/Dez.2012. disponível em: $<$ http://www.ufopa.edu.br/revistaexitus/revistas/vol.-2-no.-2-2013-2012-issn-impresso2236-2983-issn-eletronico-2237-9460/artigos/o-papel-da-monitoria-para-a-formacaode-professores-cenarios-itinerarios-e-possibilidades-no-contexto-atual/view $>$. Acesso em: 12 nov. 2012.

BASTOS, Maria Helena Camara. O Ensino monitoral/mútuo no Brasil (1827-1854). In STEPHANOU, Maria; BASTOS, Maria Helena Camara (Org.). Histórias e Memórias da educação no Brasil: século XIX. Petrópolis, RJ: Vozes, 2005. p.34-51.

. Independências e educação na américa latina: as experiências lancasterianas no século XIX. Cadernos de História da Educação - v.10, n.1 jan/jun. 2011. Disponível em < http://www.seer.ufu.br/index.php/che/article/view/13151 >

BICUDO, M. A. V. Pesquisa Qualitativa: Significados e a Razão que a Sustenta. In: Revista pesquisa qualitativa/publicação da Sociedade de Estudos e Pesquisas Qualitativas - Ano 1, n. 1 (2005) - São Paulo: SE\&PQ, 2005.

BORBA, Marcelo de Carvalho; PENTEADO, Miriam. Informática e educação matemática. 3.ed. rev. Belo Horizonte: Autêntica, 2003.

BORBA, Marcelo de Carvalho; PENTEADO, Mirian Godoy. Informática e Educação. 3. Ed. $2^{a}$ reimp. Belo Horizonte: Autêntica, 2007. 100 p.

BORBA, M. C.; VILLARREAL, M. E. Humans-With-Media and the Reorganization of Mathematical Thinking: information and communication technologies, modeling, experimentation and visualization. v. 39, New York: Springer, 2005.

COLL, C.; POZO, J.I.; SARABIA, B.; VALLS, E. Os conteúdos da reforma. Porto Alegre, Artes Médicas, 1998.

DELEUZE, G. Foucault (C. Martins, Trad.). São Paulo: Brasiliense, 2005.

O que é um dispositivo? In: G. Deleuze, O mistério de Ariana (pp. 83-

96). Lisboa: Vega, 1996. 
DURAN, D.; VIDAL, V. Tutoria: aprendizagem entre iguais. Porto Alegre: Artmed, 2007.

FOUCAULT, M. História da sexualidade I: a vontade de saber (M. Albuquerque \& Albuquerque, Trads.). 21ำ reimpressão. Rio de Janeiro: Graal, 2011.

(pp. 243-276). Rio de Janeiro: Graal, 1995.

. In: M. Foucault,

FREIRE,P. Pedagogia da Autonomia: saberes necessários à prática educativa. São Paulo: Paz e Terra, 1997.

GALLO, Sílvio. Eu, o outro e tantos outros: educação, alteridade e filosofia da diferença.

In: Anais do II Congresso Internacional Cotidiano: Diálogos sobre Diálogos. Universidade Federal Fluminense, Rio de Janeiro, 2008.

KENSKI, V. Novas Tecnologias: o rendimensionamento do espaço e do tempo e os impactos no trabalho docente. Revista Brasileira de Educação, AMPED, mai/jun/jul/ago. 1998, n. 8, p.58-71.

KOHAN, W. Entre Deleuze e a educação. Revista Educação e Realidade: Dossiê Gilles Deleuze, Porto Alegre, v. 27, n. 2, 2002, p. 123-130.

LABORDE, C. Dynamic Geometry Environments as a Source of Rich Learning Contexts for the Complex Activity of Proving. Educational Studies Mathematics, Dordrecht, v. 44, n.1/2, p. 151-161, 2000.

LÉVY, P. As Tecnologias da Inteligência: o futuro do pensamento na era da informática. Rio de Janeiro: Editora 34, 1993.

LOPES, Roseli de Deus et. all. O uso dos computadores e da internet em escolas públicas de capitais brasileiras. In: Revista Estudos \& Pesquisas Educacionais. $n$. 1, maio 2010 - Fundação Victor Civita - São Paulo. 344 p.

LÜDKE, Menga; ANDRÉ, Marli E. D. A. Pesquisa em educação: abordagens qualitativas.São Paulo: EPU, 1986.

MANACORDA, Mario Alighiero. História da Educação: da Antiguidade aos nossos dias. $7^{\text {a }}$.ed. São Paulo: Cortez, 1999.

MONROE, Paul. História da Educação. (nova tradução e notas de Idel Becker). $10^{\mathrm{a}}$ ed. São Paulo: Editora Nacional, 1974.

MORAES, Roque; GALIAZZI, Maria do Carmo. Análise textual Discursiva. Ijuí: Unijuí, 2007.

NARODOWSKI, Mariano. Infância y poder: la conformación de la pedagogia moderna. Buenos Aires: Aique Grupo Editor, 2008.

PAPERT, Seymor. Logo: computadores e educação. São Paulo: Brasiliense, 1985. 
A máquina das crianças. Porto Alegre: ARTMED, 2007.

PRIMO, Alex.

computador.

200 .

isponível

em

http://smeduquedecaxias.rj.gov.br/nead/Biblioteca/Forma\%C3\%A7\%C3\%A3o\%20Cont inuada/Tecnologia/cibercultura/Enfoques\%20e\%20desfoques\%20no\%20estudo\%20da \%20intera\%C3\%A7\%C3\%A3o\%20mediada\%20por\%20computador.pdf. Acesso em 15 de janeiro de 2013.

Interação mútua e reativa: uma proposta de estudo. Revista Farmecos. Jan. 2000, n.12, p. 81-92.

SANTOS, S. C. Atividades de Geometria Espacial e Tecnologias Informáticas no Contexto da Educação a Distância Online. Boletim GEPEM, v. 53, p. 75-93, 2008.

SCHNEIDER, Márcia Sueli Pereira da. Monitoria: instrumento para trabalhar com a diversidade de conhecimento em sala de aula. Revista Espaço Acadêmico $n^{\circ} 65$ Outubro 2006 disponível em: <http://www.espacoacademico.com.br/065/65schneider.htm>.Acesso em: 12 nov. 2012.

SILVA, Marco. Que é interatividade. Boletim técnico do Senac, Rio de Janeiro, v. 24, n. 2, maio/ago. 1998. p. 27-35.

ULLMANN, Reinholdo, BOHNEN, Aloysio. Universidade: das origens à renascença. São Leopoldo: Ed. Unisinos, 1994.

VALENTE, J. A. Aprendendo para a vida: o uso da informática na educação especial. In: VALENTE, J. A; FREIRE, F. M. P. (Org.). Aprendendo para a vida: os computadores na sala de aula. São Paulo: Cortez, 2001.

UNICAMP. 1999a.

Computadores na Sociedade do Conhecimento. Campinas: NIED -

Por que o computador na educação? Em J.A. Valente, (org.)

Computadores e Conhecimento: repensando a educação. Campinas: Gráfica da UNICAMP, 1993, p. 24-44.

WEISS, Alba M. Lemme; CRUZ, Mara L.R.M. A informática e os problemas escolares de aprendizagem. Rio de Janeiro: DP\&A, 2001.

ZULATTO, R. B. A. Professores de Matemática que Utilizam Softwares de Geometria Dinâmica: suas características e perspectivas. Dissertação (Mestrado em Educação Matemática).Instituto de Geociências e Ciências Exatas, Universidade Estadual Paulista, Rio Claro, 2002. 